\title{
Cervid herpesvirus 2 and not Moraxella bovoculi caused keratoconjunctivitis in experimentally inoculated semi-domesticated Eurasian tundra reindeer
}

\author{
Morten Tryland ${ }^{1 *}$ (D, Javier Sánchez Romano ${ }^{1}$, Nina Marcin ${ }^{1,4}$, Ingebjørg Helena Nymo ${ }^{1}$, \\ Terje Domaas Josefsen ${ }^{2,5}$, Karen Kristine Sørensen ${ }^{3}$ and Torill Mørk ${ }^{2}$
}

\begin{abstract}
Background: Infectious keratoconjunctivitis (IKC) is a transmissible disease in semi-domesticated Eurasian reindeer (Rangifer tarandus tarandus). It is regarded as multifactorial and a single causative pathogen has not yet been identified. From clinical outbreaks we have previously identified Cervid herpesvirus 2 (CvHV2) and Moraxella bovoculi as candidates for experimental investigations. Eighteen reindeer were inoculated in the right eye with CvHV2 $(n=5), M$. bovoculi $(n=5), C v H V 2$ and M. bovoculi $(n=5)$ or sterile saline water $(n=3$; controls $)$.

Results: All animals inoculated with CvHv2, alone or in combination with M. bovoculi, showed raised body temperature, increased lacrimation, conjunctivitis, excretion of pus and periorbital oedema; clinical signs that increased in severity from day 2 post inoculation (p.i.) and throughout the experiment, until euthanasia 5-7 days p.i. Examination after euthanasia revealed corneal oedema, and three animals displayed a corneal ulcer. CvHV2 could be identified in swab samples from both the inoculated eye and the control eye from most animals and time points, indicating a viral spread from the inoculation site.

Conclusions: This study showed that CVHV2 alone and in combination with M. bovoculi was able to cause the characteristic clinical signs of IKC in reindeer, whereas inoculation of $M$. bovoculi alone, originally isolated from a reindeer with IKC, did not produce clinical signs. Previous studies have suggested that herding procedures, animal stress and subsequent reactivation of latent CVHV2 infection in older animals is a plausible mechanism for IKC outbreaks among reindeer calves and young animals in reindeer herds. However, further studies are needed to fully understand the infection biology and epidemiology associated with IKC in reindeer.
\end{abstract}

Keywords: Alphaherpesvirus, Eye disease, IKC, Moraxella, Ophthalmology, Reindeer, Wildlife

\section{Background}

Infectious keratoconjunctivitis (IKC) has been reported in semi-domesticated Eurasian tundra reindeer (Rangifer tarandus tarandus) in Fennoscandia for more than a century [1], causing outbreaks among calves of the year $(<1$ year) and young animals particularly [2-4]. The first

\footnotetext{
*Correspondence: morten.tryland@uit.no

${ }^{1}$ Arctic Infection Biology, Department of Arctic and Marine Biology,

UiT-The Arctic University of Norway, POBox 6050, Langnes, 9037 Troms $\varnothing$, Norway

Full list of author information is available at the end of the article
}

sign of the disease is increased lacrimation observed as an untidy and miscoloured periocular hair coat followed by conjunctivitis and increasing periorbital and corneal oedema. The oedema is giving the eye an opaque, and whitish to bluish appearance (Fig. 1a), which is how IKC is usually recognized in the field by reindeer herders. In the absence of spontaneous healing, the infection progresses with an increasing severity of conjunctivitis and oedema, corneal ulceration, and panophthalmitis leading to permanent blindness (Fig. 1b). For reindeer, that spend most of the year free-ranging and unattended, this 

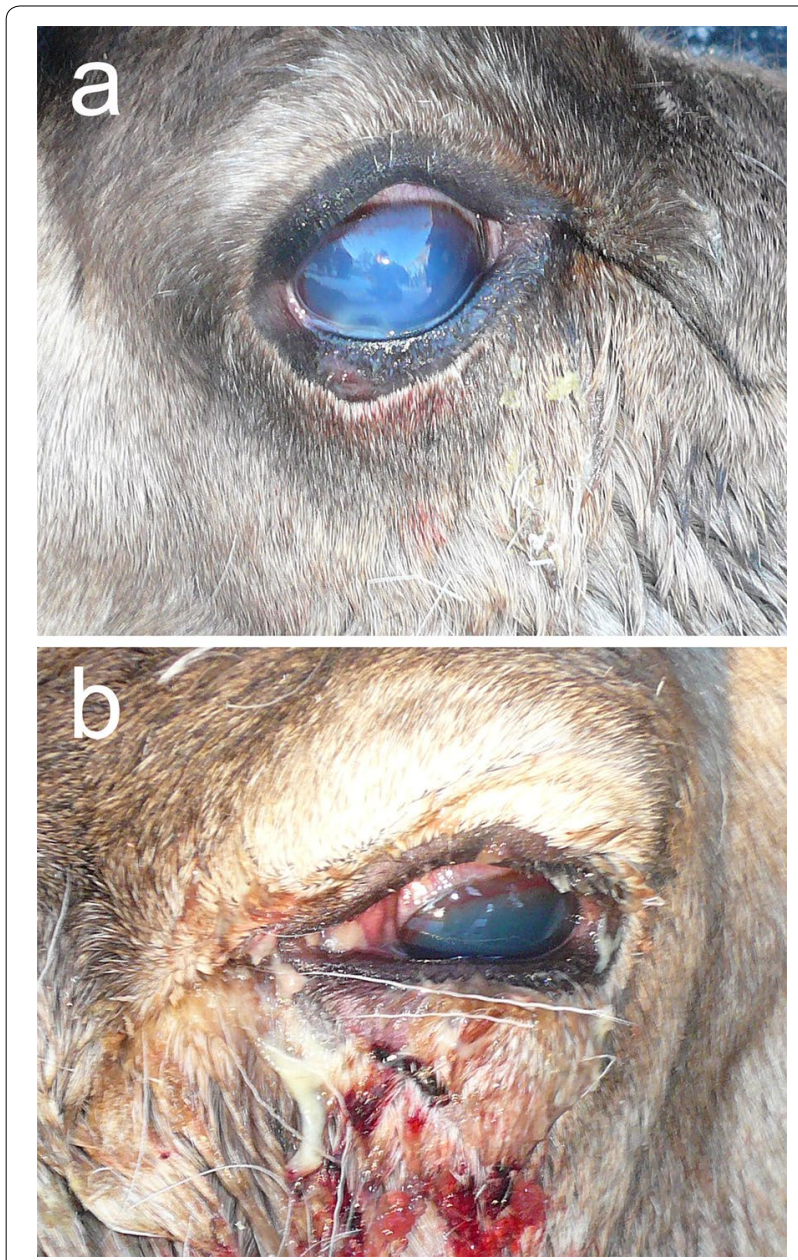

Fig. 1 Infectious keratoconjunctivitis (IKC) during an outbreak among free-ranging Eurasian semi-domesticated tundra reindeer (Rangifer tarandus tarandus): a corneal oedema indicated by an opaque and discolored cornea. b Severe grade of IKC with panophthalimitis, oedema and haemorrhage. This condition often involves corneal ulcer and may lead to permanent blindness

disease represents an important animal welfare issue as well as a potential source of economic loss for the herders $[2,4]$.

In spite of long-term awareness of IKC in reindeer, a causative agent has not yet been identified and IKC in reindeer is regarded as a multi-factorial disease, similar to infectious bovine keratoconjunctivitis (IBK), commonly referred to as "pinkeye" in cattle. The Gramnegative bacterium Moraxella bovis is suggested as the causative agent of IBK [5], although recent studies have shown that Moraxella bovoculi, originally identified in 2002 and shown to be distinct from M. bovis, may also be associated with IBK $[6,7]$. A disease similar to IKC has also been documented in sheep and goats [8,9], as well as in a wide range of wild animal species, such as moose (Alces alces), mule deer (Odocoileus hemionus), ibex
(Capra ibex), chamois (Rupicapra rupicapra), roe deer (Capreolus capreolus) and red deer (Cervus elaphus). Many different infectious agents have been associated with the disease in the different species [10-14], of which the majority have been bacteria, including known potential pathogens such as Mycoplasma spp.

Similarly, many different bacteria have been isolated from reindeer with IKC, such as M. bovoculi, M. ovis, Pasteurella multocida, and Trueperella pyogenes [2-4, 15, 16]. In a recent study of reindeer in Norway, Sweden and Finland, analyses of swab samples from the conjunctiva of clinically healthy reindeer and of reindeer with clinical IKC, showed that M. bovoculi was the bacterial agent that was most prevalent [17].

However, during an outbreak of IKC in reindeer in Troms County, Norway, the reindeer alphaherpesvirus, cervid herpesvirus 2 (CvHV2), was identified as the primary infectious agent based on the finding of this virus during the early clinical stages of the disease. Bacteria such as $M$. bovoculi seemed to dominate during later stages of IKC along with declining virus titers from the swab samples of the conjunctiva of affected animals [4].

In addition, environmental factors such as stress associated with gathering, corralling, handling and transport, reduced body condition or emaciation, exposure to UV light, and a dry and dusty environment may impact the pathogenesis of IKC in reindeer [2, 18, 19]. During natural outbreaks of IKC in reindeer, it is difficult to gain an overview of which potential pathogens are involved. It is also challenging to conduct a controlled sampling regime and to register the onset and development of disease. In addition, it is difficult to control environmental factors. In this study, reindeer calves $<1$ year old were inoculated with CvHV2 and $M$. bovoculi, which are considered the two most relevant candidates for IKC $[4,17]$. The aim of this study was to investigate if experimental inoculation with CvHV2, M. bovoculi, or a combination of the two agents, was able to cause clinical IKC in reindeer.

\section{Methods \\ Animals}

Semi-domesticated Eurasian tundra reindeer $(\mathrm{n}=27)$ calves, approximately 11 months old, were gathered from their mountain pastures. They were corralled and physically restrained for ID-tagging (plastic collar) and sampling to check for previous exposure to CvHV2 and $M$. bovoculi. Blood was obtained with a vacutainer system from the jugular vein and serum prepared by centrifugation and stored at $-20{ }^{\circ} \mathrm{C}$. For virological investigation, sterile cotton swabs were used to sample the conjunctiva bilaterally, the nostrils and the vagina (females). Swabs were subsequently placed in $1.8 \mathrm{ml}$ cryotubes with $800 \mu \mathrm{l}$ of Eagle's minimum essential medium (EMEM) 
containing antibiotics $(10,000 \mathrm{U} / \mathrm{ml}$ penicillin and $10 \mathrm{mg} /$ $\mathrm{ml}$ streptomycin; $1 \mathrm{ml} / \mathrm{l}$ of gentamicin, $50 \mathrm{mg} / \mathrm{ml}$ and $10 \mathrm{ml} / \mathrm{l}$ of amphotericin B $250 \mu \mathrm{g} / \mathrm{ml}$; EMEMab $10 \mathrm{ml} / \mathrm{l}$ ) and stored at $-80^{\circ} \mathrm{C}$. For bacteriological investigation, a swab (Transwab ${ }^{\mathrm{R}}$, Medical Wire \& Equipment, Wiltshire, UK) was introduced into both conjunctivae, rubbed gently against the mucosal lining and placed in its transport medium container. Blood samples were tested for antibodies against CvHV2. Swab samples from the conjunctiva and nostrils were tested for the presence of CvHV2 DNA (nested polymerase chain reaction [PCR]), whereas swab samples from conjunctiva were tested for $M$. bovoculi (cultivation), as described below. Based on the test results, 21 animals (5 females and 16 males) with no indication of previous exposure to CvHV2 or M. bovoculi were recruited to the study. The animals were corralled together in a fence (see below) for a habituation period of four weeks before inoculation. The inoculation experiment lasted for a total of 15 days.

All animals were chemically immobilized and weighed twice during the study, i.e. on day 0 (inoculation) and on the day of euthanasia. Animals were immobilized by darting (Dan-Inject JM Special; Dan-Inject ApS, Børkop, Denmark) using a combination of medetomidine (Zalopine ${ }^{\circledR} 10 \mathrm{mg} / \mathrm{ml}$, Orion Corporation Animal Health, Espoo, Finland) and ketamine (Ketalar ${ }^{\circledR}$ $50 \mathrm{mg} / \mathrm{ml}$, Pfizer AS, Oslo, Norway) at a fixed ratio of 1:5 (mg:mg) medetomidine:ketamine. When the inoculation process was completed, sedation was reversed by intramuscular injection of atipamezole (Antisedan ${ }^{\mathrm{TM}}$; Atipamezole $5 \mathrm{mg} / \mathrm{ml}$, Zoetis, UK) at a fixed ratio of 5:1 atipamezole:medetomidine and animals were monitored until they were standing. Despite using recommended drugs and doses being reduced to one-third of those recommended for semi-domesticated reindeer [20], three reindeer (one female, two males) died from acute shocklike complications. Similar complications did not occur during the second round of chemical immobilization using the same drugs and doses. When chemically immobilized, body temperature was measured with a digital clinical thermometer (Fluke Thermometer 51/52 II; Fluke Norge, Oslo, Norway), with a sensor positioned $30 \mathrm{~cm}$ inside the rectum. Pulse rate and arterial oxyhemoglobin $\left(\mathrm{SpO}_{2}\right)$ was measured with a handheld pulse oximeter (Masimo RAD 57; Masimo International Sàrl, Neuchatel, Switzerland) with the clip-sensor applied to the tongue. Respiratory rate was recorded by counting breathing movements of the chest using a stopwatch.

Animals were euthanized at different time points during the experiment using a captive bolt stunning gun followed by bleeding of the jugular vein. Animals R19 (CvHV2-group) and R16 (M. bovoculi group) were euthanized on day 2 and 3 respectively, due to fracture of the femur. Animals in the two groups inoculated with CvHV2 (alone or in combination with M. bovoculi) were euthanized according to defined animal welfare end-points on days 3-7 post inoculation (p.i.) (Table 1 ). Remaining animals of the M. bovoculi group were euthanized on day 6 $(\mathrm{n}=1)$ and day $13(\mathrm{n}=3)$ p.i., whereas the control animals $(n=3)$ were euthanized on day 15 p.i. Animals with no other clinical symptoms besides those observed in the eyes were sampled in the animal experimental facility, whereas animals with trauma and animals that experienced respiratory distress upon chemical immobilization were subjected to a full necropsy in an attempt to determine the cause of these unexpected complications.

\section{Animal facility, feeding and handling}

Animals were introduced to an outdoor field research facility on May 6th, 2014. The corral consists of one large pen (approx. $100 \times 80 \mathrm{~m}$ ) and four smaller pens (approx. $50 \times 50 \mathrm{~m}$ ), all separated from each other and from the surrounding areas by $2.5 \mathrm{~m}$ high steel wire fences. The ground inside the pens was covered with a deep layer of snow in the beginning, but due to snow melting and greening in the spring, fresh grass pasture became available. Animals were ID-tagged with an ear tag and by spraying a number on the fur on both sides of the body to ensure easy identification. They were corralled together for the first four weeks (habituation period) to get used to the facility, the feed and the presence of people.

The animals were fed lichen (Cladina spp.), which was gradually replaced by commercial pelleted feed for reindeer (Reinsdyrfôr, Felleskjøpet, Trondheim, Norway). 1 week before inoculation and throughout the remaining experiment, the animals were fed pellets ad libitum, supplemented with lichen. Fresh water was provided and changed on a daily basis. Body condition, evaluated by visual inspection and palpation, varied from medium to lean, but increased during the habituation period. On the day of inoculation, the animals weighed 37-59 kg (mean $49.1 \mathrm{~kg}$ ) and were separated into four groups without further contact (Control, CvHV2, M. bovoculi and CvHV2/M. bovoculi).

During the entire study, the animals were fed and inspected three times a day by veterinarians licenced for conducting animal experiments. A record was kept describing the behaviour of each animal, condition, food intake and interactions between animals as well as development of clinical signs.

Except for day 0 (inoculation) and on the day of euthanasia at varying time points p.i. when animals were chemically immobilized, all other close inspections and sampling were conducted during physical restraint. However, on days when animals were not handled, the evaluation and development of clinical signs was observed at a distance of a few metres with binoculars. 
Table 1 Clinical signs from the right eye of 10 semi-domesticated Eurasian tundra reindeer (Rangifer tarandus tarandus) after inoculation with cervid herpesvirus $2\left(C^{2} H V 2 ; n=5\right)$ or a combination of CvHV2 and Moraxella bovoculi $(n=5)($ data from animals inoculated with $M$. bovoculi alone or from control animals are not shown)

\begin{tabular}{|c|c|c|c|c|c|c|c|c|c|}
\hline Inoculum & ID & Day 0 & Day 1 & Day 2 & Day 3 & Day 4 & Day 5 & Day 6 & Day 7 \\
\hline \multirow[t]{5}{*}{ CvHV2 } & R4 & None & & $\begin{array}{l}\text { Pus }(2)^{a} \\
\text { P-oedema }(1)^{b} \\
\text { Conjunctivitis }\end{array}$ & $\begin{array}{l}\text { Pus (2) } \\
\text { P-oedema (3) }\end{array}$ & $\begin{array}{l}\text { Lacrimation } \\
\text { P-oedema (3) }\end{array}$ & $\begin{array}{l}\text { Pus (3) } \\
\text { P-oedema (3) } \\
\text { Corneal } \\
\quad \text { oedema } \\
\text { T: } 40.3\end{array}$ & $\begin{array}{l}\text { Pus (3) } \\
\text { P-oedema (3) }\end{array}$ & $\begin{array}{l}\text { Pus (3) } \\
\text { P-oedema (3) } \\
\text { Conjunctivitis } \\
\text { Corneal oedema } \\
T: 39.8\end{array}$ \\
\hline & R5 & None & & $\begin{array}{l}\text { Pus (1) } \\
\text { P-oedema (1) }\end{array}$ & $\begin{array}{l}\text { Pus (3) } \\
\text { P-oedema (2) }\end{array}$ & $\begin{array}{l}\text { Pus (3) } \\
\text { P-oedema (3) }\end{array}$ & $\begin{array}{l}\text { Pus (3) } \\
\text { P-oedema (3) } \\
\text { Corneal oedema } \\
\text { Corneal ulcer: } \\
\quad 12 \mathrm{~mm} \\
\text { T: } 40.5\end{array}$ & & \\
\hline & R10 & None & & $\begin{array}{l}\text { Pus (3) } \\
\text { P-oedema (1) } \\
\text { Conjunctivitis }\end{array}$ & $\begin{array}{l}\text { Pus (3) } \\
\text { P-oedema (2) }\end{array}$ & $\begin{array}{l}\text { Pus (3) } \\
\text { P-oedema (3) }\end{array}$ & $\begin{array}{l}\text { Pus (3) } \\
\text { P-oedema (3) } \\
\text { Conjunctivitis } \\
\text { Corneal oedema } \\
\text { T: } 40.0\end{array}$ & & \\
\hline & R19 & None & & $\begin{array}{l}\text { Lacrimation } \\
\text { Pus (1) } \\
\text { P-oedema (1) c }\end{array}$ & & & & & \\
\hline & $\mathrm{R} 21$ & None & & P-oedema (1) & $\begin{array}{l}\text { Lacrimation } \\
\text { Pus (2) } \\
\text { P-oedema (2) }\end{array}$ & $\begin{array}{l}\text { Lacrimation } \\
\text { Pus (2) } \\
\text { P-oedema (2) }\end{array}$ & $\begin{array}{l}\text { Pus (2) } \\
\text { P-oedema (2) } \\
\text { Corneal } \\
\text { oedema } \\
\text { Corneal ulcer: } \\
4 \mathrm{~mm}\end{array}$ & $\begin{array}{l}\text { Pus (3) } \\
\text { P-oedema (3) } \\
\text { Corneal oedema } \\
\text { Corneal ulcer: } \\
\quad 10 \mathrm{~mm} \\
\text { T: } 40.1\end{array}$ & \\
\hline \multirow[t]{5}{*}{$\begin{array}{l}\text { CvHV2 and } M . \\
\text { bovoculi }\end{array}$} & $\mathrm{R} 1$ & None & Pus (1) & $\begin{array}{l}\text { Lacrimation } \\
\text { Pus (1) } \\
\text { P-oedema (1) } \\
\text { Red sclera }\end{array}$ & $\begin{array}{l}\text { Lacrimation } \\
\text { Pus (2) } \\
\text { P-oedema (2) }\end{array}$ & $\begin{array}{l}\text { Pus (2) } \\
\text { Lacrimation } \\
\text { P-oedema (2) }\end{array}$ & $\begin{array}{l}\text { Pus (3) } \\
\text { P-oedema (3) } \\
\text { Corneal } \\
\quad \text { oedema } \\
\text { T: } 40.4\end{array}$ & $\begin{array}{l}\text { Pus (3) } \\
\text { P-oedema (3) }\end{array}$ & $\begin{array}{l}\text { P-oedema (3) } \\
\text { Conjunctivitis } \\
\text { Corneal oedema } \\
\text { Corneal ulcer: } \\
3 \mathrm{~mm} \\
\text { T: } 39.1\end{array}$ \\
\hline & R3 & None & & $\begin{array}{l}\text { Lacrimation } \\
\text { P-oedema (1) }\end{array}$ & $\begin{array}{l}\text { Pus (3) } \\
\text { P-oedema (3) }\end{array}$ & $\begin{array}{l}\text { Pus (3) } \\
\text { P-oedema (3) }\end{array}$ & $\begin{array}{l}\text { P-oedema (3) } \\
\text { Adherent pus } \\
\text { Blue cornea } \\
\text { T: } 40.0\end{array}$ & $\begin{array}{l}\text { Pus (3) } \\
\text { Conjunctivitis } \\
\text { Corneal oedema } \\
T: 39.8\end{array}$ & \\
\hline & R7 & None & & Pus (1) & $\begin{array}{l}\text { Pus (2) } \\
\text { Lacrimation } \\
\text { P-oedema (2) }\end{array}$ & $\begin{array}{l}\text { Pus (2) } \\
\text { Lacrimation } \\
\text { P-oedema (2) }\end{array}$ & $\begin{array}{l}\text { Pus (3) } \\
\text { P-oedema (3) } \\
\text { Conjunctivitis } \\
\text { Corneal oedema } \\
T: 40.3\end{array}$ & & \\
\hline & $\mathrm{R} 13$ & None & & $\begin{array}{l}\text { Pus (1) } \\
\text { Lacrimation } \\
\text { Red sclera } \\
\text { P-oedema (2) }\end{array}$ & $\begin{array}{l}\text { Pus (3) } \\
\text { Lacrimation } \\
\text { P-oedema (2) }\end{array}$ & $\begin{array}{l}\text { Pus (3) } \\
\text { P-oedema (3) } \\
\text { Conjunctivitis } \\
\text { Corneal oedema } \\
T: 40.4\end{array}$ & & & \\
\hline & $\mathrm{R} 17$ & None & Dry cornea & $\begin{array}{l}\text { Pus (1) } \\
\text { Lacrimation } \\
\text { P-oedema (2) }\end{array}$ & $\begin{array}{l}\text { Pus (3) } \\
\text { P-oedema (2) } \\
\text { T: } 40.9\end{array}$ & & & & \\
\hline
\end{tabular}

Clinical signs are indicated, relative to the day of inoculation (day 0). Observations during day 1, day 3, day 4 and day 6 were conducted without handling the animals, whereas all animals were captured (physical restraint) and sampled at day 2 and day 5

The time of euthanasia for each animal is indicated with italic text

a Pus: (1) small amounts (clots), (2) large amounts, and (3) huge amounts of pus, adherent to eyelids/skin and covering the eye

b P-oedema: periorbital oedema: (1) slight swelling of conjunctiva, (2) severe oedema, and (3) extensive oedema, periorbital tissues covering the eyeball

c Euthanized due to trauma 


\section{Preparation of inocula}

CvHV2 was originally isolated from the conjunctiva of a reindeer with clinical IKC [4]. The virus was propagated in Madin-Darby bovine kidney (MDBK) cells (ATCC CCL22) in EMEM supplemented with 10\% horse serum (LGC Standards, Middlesex, UK). Virus cultures were harvested when more than $90 \%$ of the cells showed cytopathic effect (CPE). Cellular debris was removed by centrifugation $(7800 \mathrm{~g}, 30 \mathrm{~min})$ and viral particles in the supernatant were pelleted through a $30 \%$ sucrose cushion $(20,000 \mathrm{~g}, 1 \mathrm{~h})$, re-suspended in $5 \mathrm{ml} \mathrm{PBS}$, filtered through a $0.45 \mu \mathrm{m}$ cellulose filter (Merck Millipore, Darmstadt, Germany) and frozen at $-80{ }^{\circ} \mathrm{C}$. The virus titre of the inoculum was $5.8 \times 10^{6} \mathrm{TCID}_{50} / \mathrm{ml}$.

The M. bovoculi strain used for inoculation was originally cultivated from a swab sample from the conjunctiva of a Norwegian reindeer with clinical IKC in 2014. The colonies were $2-3 \mathrm{~mm}$ in diameter, yellow/grey, round, with a shiny "fat" appearance, and revealed beta-haemolysis after $24 \mathrm{~h}$ growth on blood agar. The colonies grew at $37{ }^{\circ} \mathrm{C}$, but only in aerobic conditions (without $\mathrm{CO}_{2}$ ). The bacteria were Gram negative with a coccoid form, and the catalase and oxidase tests were positive. Potential virulence factors were not investigated. The isolate was verified as $M$. bovoculi by $16 \mathrm{~s}$ rRNA sequencing (data not shown). After storage $\left(-80^{\circ} \mathrm{C}\right)$, the isolate was cultivated on $5 \%$ sheep blood agar at $37{ }^{\circ} \mathrm{C}$ under aerobic conditions for $24 \mathrm{~h}$ prior to inoculation. The bacterium underwent a total of four in vitro passages (from isolation to inoculation).

\section{Inoculation}

While the animals were sedated, both eyes were photographed and checked for general clinical signs and for corneal ulcers using the fluorescein test (Fluoresceinnatrium Minims $20 \mathrm{mg} / \mathrm{ml}$; Chauvin, Surrey, UK). Disposable coats and gloves were used by all persons involved in the inoculation and sampling of the animals. For any intervention with the animals (feeding, inoculation, sampling), the control group was visited before the inoculated animals.

Prior to inoculation and at each of the following inspections, eyes were photographed, sampled (swab) and checked for corneal ulcers using fluorescein, followed by thorough flushing of the eyes with sterile water. Local anaesthesia (Oxibuprokain Minims $4 \mathrm{mg} / \mathrm{ml}$; Chauvin) was applied in the right eye 4 min prior to a mild rubbing of the conjunctival mucosa with sterile sandpaper (grade 60).

The virus was inoculated by introducing a small sterile cotton cushion, soaked in PBS/CvHV2, to the conjunctiva under the lower eyelid and keeping it there for 4 min. $M$. bovoculi was inoculated by picking a colony of $M$. bovoculi from the agar plate with a sterile cotton stick and spreading it onto the rubbed area of the conjunctiva. Bacterial colonies from the same plate were subsequently reseeded onto new agar plates to check for viability. These procedures for viral and bacterial inoculations were conducted to allow access of virus and bacteria in excess to slightly scarified mucosal cells of the conjunctiva. When inoculating both CvHV2 and M. bovoculi in the same eye, the virus was inoculated first, followed by the bacterium after $10 \mathrm{~min}$. For the animals in the control group, a sterile cotton stick was soaked in sterile water and applied onto the rubbed conjunctiva. The left eye was inspected as described above, but not further manipulated, and served as a control for each animal (all groups).

\section{Bacterial cultivation}

Swab samples from the conjunctiva of both eyes, obtained on the day of inoculation (Day 0) and every second day after inoculation, were subjected to cultivation on a $5 \%$ sheep blood agar plate. The plates were incubated aerobically at $37{ }^{\circ} \mathrm{C}$ and inspected after 24 and $48 \mathrm{~h}$. Bacterial colonies that were yellow to grey of colour, 2-3 $\mathrm{mm}$ in diameter, with a shiny "fat" appearance and were beta-haemolytic, were suspected to be Moraxella spp. Such colonies were sub-cultured for purity and further characterized (morphology, Gram staining, catalase, oxidase). Selected isolates were subsequently identified to species level (score $>2$ ) by MALDI-TOF mass spectrometry (Microflex; Bruker UK Limited, Coventry, UK).

\section{DNA extraction, PCR and sequencing}

To verify that the animals did not harbour CvHV2 viral particles in the conjunctival mucosa prior to the experiment, DNA was extracted from swabs obtained from the conjunctival mucosa (QIAamp ${ }^{\circledR}$ DNA Mini Kit, Hilden, Germany) with a mean output of $8.1 \mathrm{ng} / \mu \mathrm{l}(\mathrm{SD}=8.0)$ and a nested PCR was conducted as described previously [21]. The inner primer set amplified a $294 \mathrm{bp}$ region of the $U L 27$ gene encoding glycoprotein $\mathrm{B}(\mathrm{gB})$, which is a highly conserved gene region among ruminant alphaherpesviruses [22]. CvHV2 (strain Salla 82) [23] and BoHV1 [24] were used as positive controls. PCR amplicons were separated by agarose gel electrophoresis and visualized with ethidium bromide (Sigma-Aldrich Norway AS, Oslo, Norway).

A quantitative real-time Taqman Probe based PCR (qPCR), amplifying a $95 \mathrm{bp}$ fragment in a different region of the UL27 gene as compared to the nested PCR and shown previously to detect Rangiferine herpesvirus (now designated $\mathrm{CvHV}$ ), was performed as described previously [25]. The PCR was conducted with two slight modifications; the annealing temperature was reduced to $58.9^{\circ} \mathrm{C}$ (following thermal gradient analysis) and the volume of nuclease-free water was increased from 4.0 to $4.5 \mu \mathrm{l}$ for a 
total reaction volume of $25 \mu \mathrm{l}$. Samples were run in duplicates. A positive control (CvHV2, used as inoculum) [4], a negative control (DNA extracted from muscular tissue of a CvHV2 seronegative control animal), and a non-template control containing all PCR-components except DNA were included on each plate. This technique was used to analyse all eye swab and plasma samples collected from day 0 and throughout the experiment.

PCR amplicons were prepared for nucleotide sequencing by enzymatic removal of unused dNTP and primers (ExoSAP-IT $^{\mathrm{TM}}$; Amersham Pharmacia Biotech, Sweden), after which sequencing was conducted (BigDye ${ }^{\circledR}$ Terminator v3.1 cycle sequencing kit; Applied Biosystems, Norway) in an Applied Biosystems 3130 XL Genetic Analyzer (Applied Biosystems).

\section{Serology}

Serum samples were investigated for anti-alphaherpesvirus antibodies using a commercial bovine enzyme-linked immunosorbent assay (ELISA; gB Blocking, LSI Laboratoire Service International, Lissieu, France) based on BoHV1 glycoprotein B (gB) as an antigen. The kit was previously validated against a virus neutralization test (VNT) for analyzing reindeer serum samples for antiCvHV2 antibodies [26]. All serum samples were tested in duplicate and evaluated against bovine (provided with the kit) and reindeer [27] positive-control sera.

\section{Results}

\section{Clinical signs}

A thorough clinical examination, including body temperature measurement, was conducted on each animal when they were physically or chemically immobilized, i.e. upon arrival to the fence, on the day of inoculation one month later (day 0), and on days 2, 5, 7, 13 and 15 p.i., as well as upon euthanasia, if euthanized outside this schedule.

Body temperature $(\mathrm{n}=18)$ at the time of inoculation (day 0) varied from 37.8 to $39.5{ }^{\circ} \mathrm{C}$ (mean $39.0{ }^{\circ} \mathrm{C}$, SD 0.05). On day 5 p.i., the mean body temperature for all inoculated animals (except the controls) had increased to $39.8-40.6{ }^{\circ} \mathrm{C}$ (mean $40.2{ }^{\circ} \mathrm{C}$ ), and decreased again over the following days. Mean temperature also increased for the control animals $(\mathrm{n}=3)$, from $39.0{ }^{\circ} \mathrm{C}$ (day 0$)$ to $39.9^{\circ} \mathrm{C}$ (day 7), after which it decreased to $39.6{ }^{\circ} \mathrm{C}$ (day 10 ) and $39.3^{\circ} \mathrm{C}$ (day 15$)$.

In the CvHV2 group, no clinical signs were observed on day 1 (Table 1). On day 2, the inoculated eyes of all animals in this group displayed conjunctival oedema, four of the five animals having purulent exudate and two having hyperaemia of the conjunctiva (3). From day 3 to day 5 , the severity of the oedema typically increased from mild (grade 1) to severe (grade 3), involving the whole periorbital region by day 5 . Similarly, the suppuration increased from mild (grade 1) to severe (grade 3) (Fig. 2). Upon inspection on day 5 , two animals (R5 and R10) were euthanized, showing corneal oedema, high grades of periorbital oedema and suppuration, as well as a slightly raised body temperature, 40.5 and $40.0{ }^{\circ} \mathrm{C}$, respectively. Similar clinical signs were observed for R21 and R4, which were euthanized on day 6 and 7, respectively (Fig. 2). Animals R5 and R21 had at the time of euthanasia developed a corneal ulcer, by day 5 and day 6 , respectively.

In the $M$. bovoculi group, a grey or whitish exudate was observed associated with the lower eyelid of the
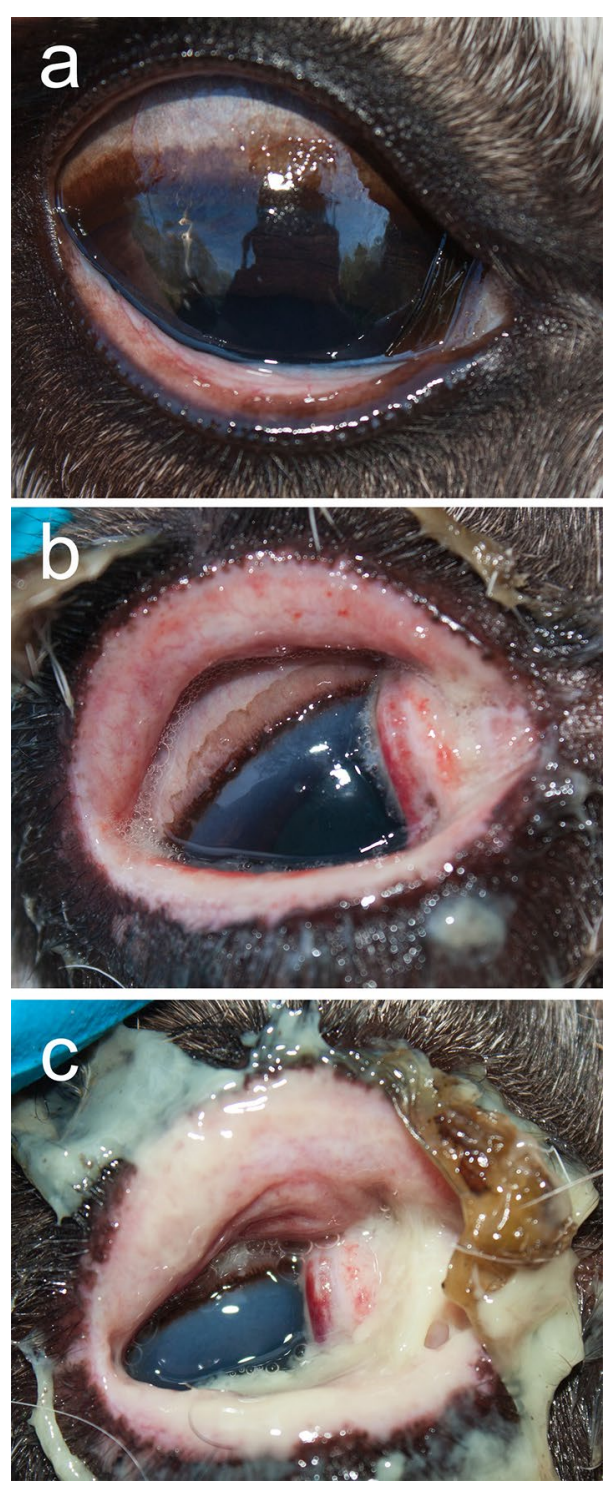

Fig. 2 Semi-domesticated Eurasian tundra reindeer (R21) experimentally inoculated with reindeer alphaherpesvirus (cervid herpesvirus 2; (VHV2). a Day 0, i.e. the day of inoculation, $\mathbf{b}$ day 5 post inoculation (p.i.), and $\mathbf{c}$ day 6 p.i. 
inoculated right eye in two animals (R6 and R8) some hours after inoculation (day 0 ) and early the following day (day 1), which thereafter disappeared. No clinical signs were observed in this group throughout the remaining period of the experiment (Fig. 3).

The clinical signs observed in the group receiving both CvHV2 and $M$. bovoculi were indistinguishable from those described for the CvHV2 group (Table 1). All animals in this group, except the one euthanized on day 3 (R17), showed suppuration and developed conjunctivitis, and corneal and periorbital oedema (Fig. 4). One animal (R1) developed a corneal ulcer.
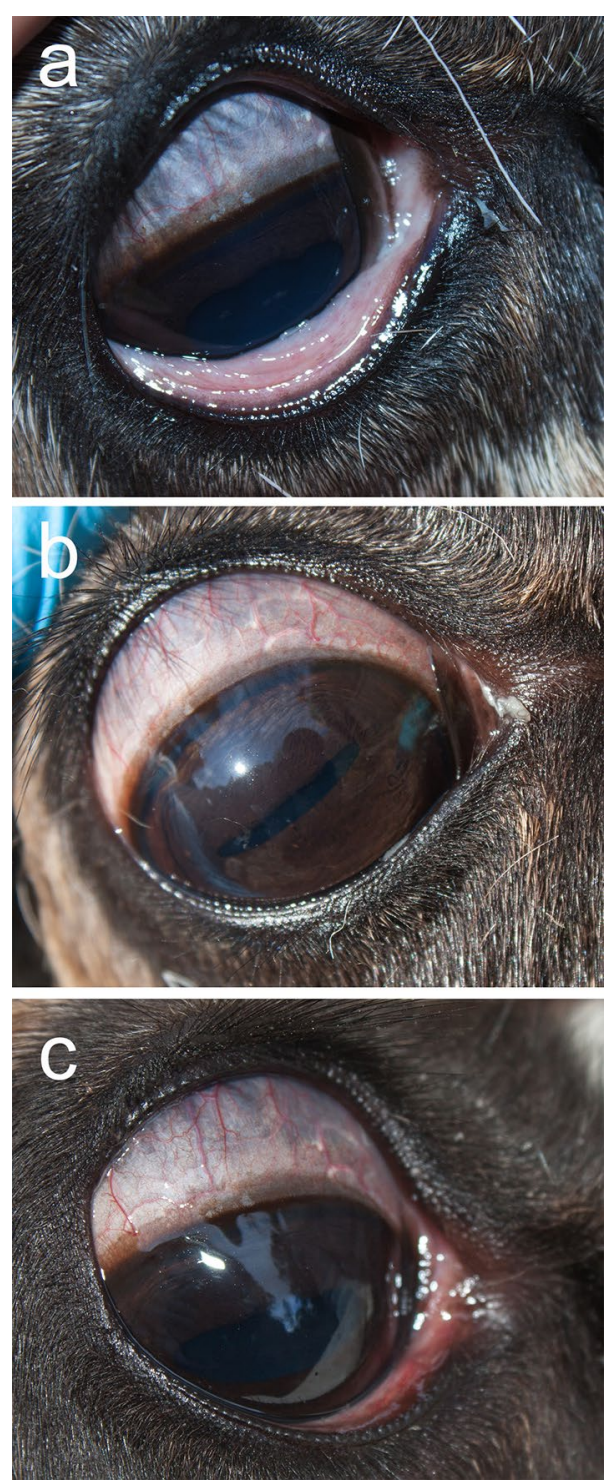

Fig. 3 Semi-domesticated Eurasian tundra reindeer (R15) inoculated with Moraxella bovculi. a Day 0, i.e. the day of inoculation, b day 5 post inoculation (p.i.), and $\mathbf{c}$ day 10 p.i.
No clinical signs of disease were recorded in the control animals (R2, R18, R20) throughout the experiment (day 0-15).

\section{Bacteriology}

On day 0 , prior to inoculation, a few colonies of $M$. bovoculi were cultured from the conjunctiva of two animals (R6 and R8) from the group to be inoculated with $M$. bovoculi, and from another two animals ( 11 and R17) from the group to be inoculated with CvHV2 and $M$. bovoculi. These isolates were all identified using the MALDI-TOF mass spectrometry. During the experiment, $M$. bovoculi was, at different time points, cultivated from all five animals inoculated with the bacterium. In the group inoculated with CvHV2 and M. bovoculi, the bacterium was cultivated from three of five animals. In the group inoculated with CvHV2 alone, $M$. bovoculi was cultivated from four of five animals. No M. bovoculi was isolated from the control animals. In most cases, $M$. bovoculi was found with few colonies in a mixed culture.

\section{PCR}

In spite of being sero-negative, CvHV2-specific DNA was detected in one eye swab (nested PCR; R21) before the experiment, and this animal was allocated to the CvHV2 group. No CvHV2-specific DNA was detected from conjunctival swab samples from this animal or any other swab samples (both eyes, all animals) taken on day 0 of the experiment, i.e. prior to inoculation. Of the animals inoculated with CvHV2, alone or in combination with $M$. bovoculi, CvHV2 specific DNA was detected (qPCR) in all samples from both inoculated and control eyes, from day 2 until the last sampling of each animal (euthanasia). There were two exceptions: CvHV2 could not be detected in the swab sample from the right (inoculated) eye of animal R3 on day 5 (the day before euthanasia, though detected again upon euthanasia, day 6), nor from the left eye (not inoculated) of animal R21 on day 6 (the day of euthanasia).

From the animals inoculated with only $M$. bovoculi, CvHV2-specific DNA was detected in one sample from the left eye of animal R6 on day 6, but besides this, all samples from animals in this group and the control group were negative for CvHV2. Viral DNA was detected in the plasma of one animal (R7) from the CvHV2-inoculated group on day 2 but not in the plasma of this animal at later time points, and not from plasma samples from any other animal during the experiment.

\section{Serology (CvHV2)}

All animals selected for the study were sero-negative for CvHV2 upon arrival and on the day of inoculation (day 0 ). Animals R21 and R4 from the group inoculated with 

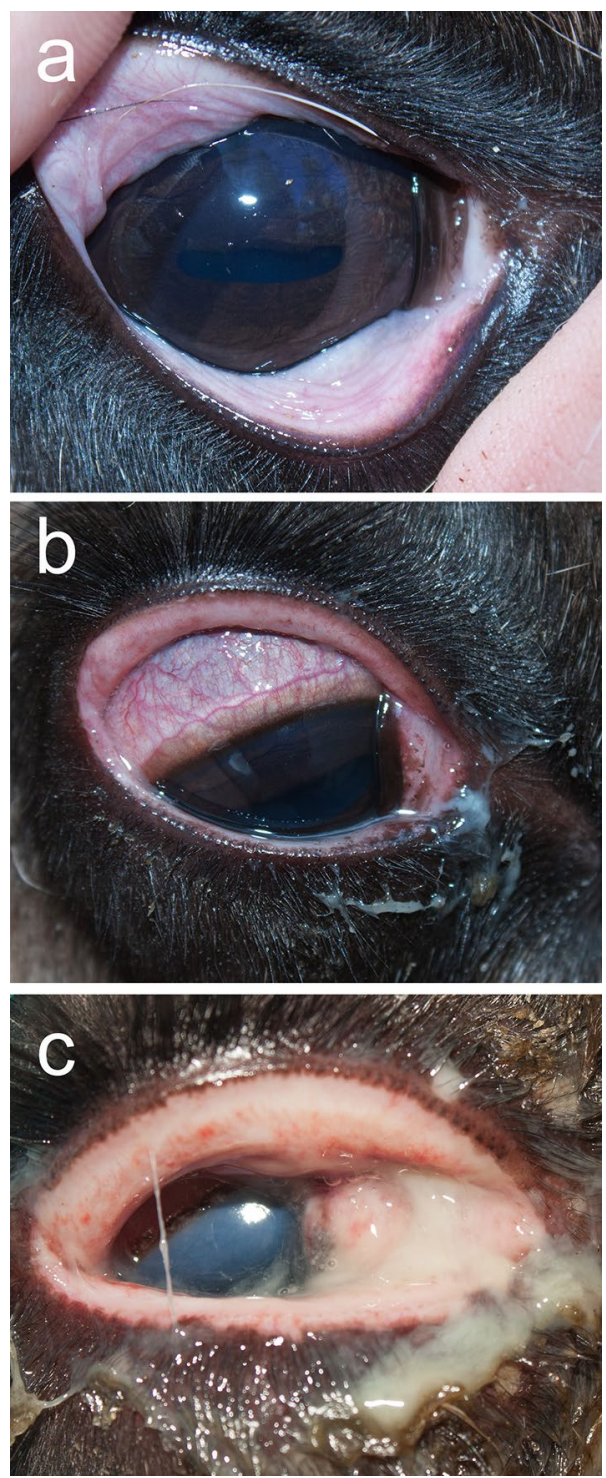

Fig. 4 Semi-domesticated Eurasian tundra reindeer (R1) inoculated with reindeer alphaherpesvirus (cervid herpesvirus 2; CVHV2) and Moraxella bovculi. a Day 0, i.e. the day of inoculation, b day 2 post inoculation (p.i.), and c day 5 p.i.

CvHV2 seroconverted on day 6 and 7, respectively, and animal R1 from the group inoculated with CvHV2 and M. bovoculi seroconverted on day 7 .

\section{Discussion}

All animals inoculated with CvHV2, alone or in combination with M. bovoculi (Figs. 2 and 4) developed clinical signs characteristic of IKC [2, 4] with a quick onset (day 2 ) and rapid progression from day 2 to days 5/6/7 (euthanasia). The animals inoculated with $M$. bovoculi alone, and the control animals, remained healthy throughout the experiment. These unambiguous clinical results, generated from an experimental inoculation of one-year-old reindeer with all members of each animal group displaying similar responses, provide powerful support of previous findings during IKC outbreaks [4], that CvHV2 is capable of causing the clinical picture that is characteristic for IKC in reindeer.

The titres of the inoculum of virus and bacteria in this study were probably high as compared to viral and bacterial transmissions under natural conditions, but nevertheless, for the virus, in line with previous reported inoculations of BoHV1 in cattle [28]. It is, however, important to keep in mind that both the virus and the bacterium are replicative agents that, once the infection is established, will multiply in permissive cells, whereas virus and bacteria in excess will be washed away from the surface linings of the eye, rendering the inoculum titres less important.

We gently rubbed a part of the conjunctival mucosa of the lower eye lid to make sure that the infectious agents had access to permissive cells upon inoculation, but we chose not to conduct scarified corneal inoculations as has been done in similar experiments using cattle and Moraxella spp. [29]. The rubbing may be somewhat similar to what reindeer may experience when corralled and exposed to sand and dust in the pen. Thus, we think the conditions under which this experiment was carried out were in many ways close to a natural setting, including the fact that animals were young $(<1$ year $)$ at the time of inoculation, and that they had been exposed to stress by being gathered from their mountain pastures, transported and corralled, and by being exposed to people and handling, all resembling natural herding conditions.

In IBK in cattle, the pathogenicity of $M$. bovis is based on the expression of a pilin protein for attachment [30] and a cytotoxin that damages the corneal epithelial cells [31]. However, M. bovoculi has also been associated with IBK. In a retrospective study of Moraxella spp. isolated from IBK outbreaks in 282 herds in 30 states of the USA, 701 were identified as $M$. bovoculi and 295 isolates as $M$. bovis [32]. It has also been shown that $M$. bovoculi isolates from cattle may have both putative cytotoxin [33] and pilin [34] genes, similar to those that have been identified in M. bovis. However, a randomized blind challenge study to assess the association between $M$. bovis and $M$. bovoculi, and IBK in 31 dairy calves, revealed that nine out of 10 calves inoculated with M. bovis developed corneal ulcers consistent with IBK, whereas none of the 10 calves inoculated with $M$. bovoculi did, although the authors stated that the pathogenicity of this particular $M$. bovoculi strain was not yet characterized [29]. This was also the situation for the M. bovoculi isolate used in our study, although it was originally isolated and identified as 
the bacterium that was dominating the bacterial growth from a swab sample obtained from the conjunctiva of a reindeer with clinical signs of IKC. Large genetic differences have recently been reported between isolates of $M$. bovoculi from eyes of cattle with IBK as compared to isolates from the nasopharynx of asymptomatic cattle, suggesting that certain genetically distinct strains of $M$. bovoculi are associated with IBK in cattle [35], which may also be the case for IKC in reindeer.

Throughout our study period, M. bovoculi was cultivated from eight of 10 animals that had been inoculated with the bacterium alone or in combination with CvHV2, but no clinical signs were associated with these findings in those inoculated with $M$. bovoculi alone. This might indicate that the isolate of M. bovoculi used for inoculation was not pathogenic, or that the duration of the bacterial infection was too short to produce clinical signs. $M$. bovoculi was also cultivated from four animals prior to inoculation (day 0), and from four animals inoculated with CvHV2 alone, from the right eye of all four animals and from both eyes of one individual. This may indicate the transmission of bacteria from other individuals, which means that $M$. bovoculi was transferred from inoculated animals into the other corrals. However, the fact that $M$. bovoculi was not cultivated from any of the control animals at any time (day 0 -day 13 p.i.) indicated that $M$. bovoculi was not introduced but rather sporadically present in apparently healthy reindeer without ocular disease. The bacterium may therefore be a commensal in the conjunctiva of reindeer as also indicated from previous bacteriological screenings [17]. Since serology for antibodies against $M$. bovoculi prior to the inoculation was not conducted, it can be argued that a lack of clinical signs in the animals inoculated with $M$. bovoculi alone may be due to a pre-existing immunity against the bacterium, but it remains uncertain if presence of the bacterium on mucosal membranes such as conjunctiva and nasopharynx would elicit a detectable humoral immune response.

Animals R1 (CvHV2 and M. bovoculi), and R4 and R21 (CvHV2) had antibodies against CvHV2 on the day of euthanasia (day 6 and 7, respectively), whereas the other animals inoculated with CvHV2 assumingly were euthanized prior to sero-conversion. This is in line with previous inoculation experiments in reindeer with CvHV2 [36], in which a humoral immune response generally was not evident until days $8-10$ p.i. Thus, the rapid onset of clinical signs after inoculation of CvHV2 in the conjunctiva indicates that a primary specific immune response will develop too late to be protective against disease in previously unexposed animals. This, and the observation that the seroprevalence among reindeer aged $<1$ year in Finnmark County, Norway, was only $8 \%$ as compared to
77\% in adults (2004-2006) [26] suggests a rapid spread of the virus among young and immunologically naïve animals, sometimes resulting in outbreaks of IKC involving hundreds of animals $[1,18]$. The hypothesis that stress causes reactivation of $\mathrm{CvHV} 2$ in latently infected animals [37] with subsequent viral shedding, exposing young and immunologically naïve animals to the virus, seems to be valid. During later stages of the disease, however, many different bacterial species, including $M$. bovoculi, have been isolated, but their role may be of a more opportunistic character, establishing infection and possibly being pathogenic once the mucosa is impacted by the CvHV2 infection. Based on the recent reports of the pathogenic properties of $M$. bovoculi in cattle, the pathogenic potential of the $M$. bovoculi isolates from reindeer should be further investigated.

No clinical signs were recorded in the three control animals, or in the left eye (control) of the inoculated reindeer (all groups). This lack of clinical signs in the left (control) eyes is in contrast to the detection of CvHV2specific DNA from the left eyes of all CvHV2-inoculated animals from day 2 until the last sampling day, with the exceptions of animal R21 on day 6 . At the same time, we were also unable to demonstrate viremia, since CvHV2specific DNA was detected in a plasma sample from only one animal (R7) at one time point (day 2) during the experiment. Thus, these results indicate that the virus was able to spread from the inoculated conjunctiva to the conjunctival mucosa of the other eye within 2 days p.i. in all CvHV2-inoculated animals,

\section{Conclusions}

Experimental inoculation of semi-domesticated reindeer revealed that $\mathrm{CvHV} 2$ is capable of inducing typical clinical signs of IKC within 2-7 days p.i., suggesting that the reindeer alphaherpesvirus, CvHV2, is the transmissible and causative agent of IKC in reindeer. The combined inoculation of $\mathrm{CvHV} 2$ and $M$. bovoculi did not change the onset, development, or the character of the clinical signs. Ocular inoculation of $M$. bovoculi alone did not produce clinical signs. M. bovoculi and other bacteria may, however, be important as opportunistic pathogens, especially during later stages of the disease. Based on the recent reports of the pathogenic properties of $M$. bovoculi in cattle $[35,38]$, the pathogenic potential of the M. bovoculi isolates from reindeer should be further investigated.

\footnotetext{
Authors' contributions

MT, TDJ and TM designed the study. MT, JSR, NM, IHN, KKS, TDJ, and TM conducted the preparations, experiment and sampling. TDJ and TM conducted the necropsy of animals and further sampling. The laboratory analyses were conducted by JSR, NM, IHN and KKS. MT drafted the manuscript. All authors contributed to the manuscript and approved the final version. All authors read and approved the final manuscript.
} 


\section{Author details}

${ }^{1}$ Arctic Infection Biology, Department of Arctic and Marine Biology, UiT-The Arctic University of Norway, POBox 6050, Langnes, 9037 Troms $\varnothing$, Norway.

${ }^{2}$ Norwegian Veterinary Institute, POBox 6050, Langnes, 9037 Tromsø, Norway.

${ }^{3}$ Vascular Biology Research Group, Department of Medical Biology, Faculty of Health Sciences, UiT-The Arctic University of Norway, Tromsø, Norway. ${ }^{4}$ Present Address: Clinique vétérinaire de l'abbatiale, 14 bis Rue Thibaut, 52220 Montier En Der, France. ${ }^{5}$ Present Address: Faculty of Bioscience and Aquaculture, Nord University, Bodø, Norway.

\section{Acknowledgements}

We thank reindeer herders for their help and patience when working with their herd during selection of experimental animals. We also thank the veterinary students Ole Christian Kjenstad and Pauline Birgitte Ulvig Kiær (Norwegian University of Life Sciences) and Trygve Vik and Jørg Vik for help during the experiments, as well as Eva Marie Breines, Ellinor Hareide (UiT-The Arctic University of Norway) and Karin-Elisabeth Holmgren (Norwegian Veterinary Institute, Tromsø, Norway) for excellent help in the laboratory. Marianne Sunde (Norwegian Veterinary Institute, Oslo, Norway) is acknowledged for conducting the $16 \mathrm{~S}$ rRNA and the MALDI-TOF mass spectrometry on the M. bovculi isolates. Sophie Scotter, UiT-Arctic University of Norway, is acknowledged for language corrections.

\section{Competing interests}

The authors declare that they have no competing interests.

\section{Availability of data and materials}

The datasets used and/or analysed during the current study are available from the corresponding author on reasonable request.

\section{Ethics approval and consent to participate}

The study followed the Guiding Principles for Biomedical Research Involving Animals developed by the Council for International Organizations of Medical Sciences (CIOMS). The motivation for the study was based on the need to identify the transmissible and causative agent of IKC in semi-domesticated reindeer to better understand the pathogenesis and to improve prophylaxis and medical treatment during disease outbreaks. The study was approved by the Norwegian Animal Research Authority (NARA; application ID 5880).

\section{Funding}

The study was funded by grants from the Norwegian Reindeer Development Fund (RUF) and Nordic Council of Ministers (NORDREGIO). The publication charges for this article have been funded by a grant from the publication fund of UiT The Arctic University of Norway.

\section{Publisher's Note}

Springer Nature remains neutral with regard to jurisdictional claims in published maps and institutional affiliations.

Received: 27 January 2017 Accepted: 19 April 2017

Published online: 24 April 2017

\section{References}

1. Bergman A. Contagious keratitis in reindeer. Scand Vet J. 1912;2:145-77.

2. Rehbinder C, Nilsson A. An outbreak of kerato-conjunctivitis among corralled, supplementary fed, semi-domesticated reindeer calves. Rangifer. 1995;15:9-14

3. Oksanen A. Keratoconjunctivitis in a corralled reindeer. Proceedings of the seventh Nordic Workshop on Reindeer Research. Rangifer Report. 1993;1:50

4. Tryland M, das Neves CG, Sunde M, MørkT. Cervid herpesvirus 2 the primary agent in an outbreak of infectious keratoconjunctivitis in semidomesticated reindeer. J Clin Microbiol. 2009;47:3707-13. doi:10.1128/ JCM.01198-09.

5. Angelos JA. Infectious bovine keratoconjunctivitis (pinkeye). Vet Clin North Am Food Anim Pract. 2015;31:61-79.
6. Angelos JA, Spinks PQ, Ball LM, George LW. Moraxella bovoculi sp. nov., isolated from calves with infectious bovine keratoconjunctivitis. Int J Syst Evol Microbiol. 2007;57:789-95.

7. Angelos JA. Moraxella bovoculi and infectious bovine keratoconjunctivitis: cause or coincidence? Vet Clin North Am Food Anim Pract. 2010;26:73-8. doi:10.1016/j.cvfa.2009.10.002.

8. Åkerstedt J, Hofshagen M. Bacteriological investigation of infectious keratoconjunctivitis in Norwegian sheep. Acta Vet Scand. 2004;45:19-26.

9. Gupta S, Chahota R, Bhardwaj B, Malik P, Verma S, Sharma M. Identification of Chlamydia and Mycoplasma species in ruminants with ocular infections. Lett Appl Microbiol. 2015;60:135-9. doi:10.1111/lam.12362.

10. Dubay SA, Williams ES, Mills K, Boerger-Fields AM. Association of Moraxella ovis with keratoconjunctivitis in mule deer and moose in Wyoming. J Wildl Dis. 2000;36:241-7.

11. Giacometti M, Janovsky M, Belloy L, Frey J. Infectious keratoconjunctivitis of ibex, chamois and other caprinae. Rev Sci Tech. 2002;21:335-45.

12. Gortázar C, Fernández-de-Luco D, Frölich K. Keratoconjunctivitis in a free-ranging red deer (Cervus elaphus) population in Spain. Z Jagdwiss. 1998;44:257-61.

13. Mavrot F, Vilei EM, Marreros N, Signer C, Frey J, Ryser-Degiorgis MP. Occurrence, quantification and genotyping of Mycoplasma conjunctivae in wild Caprinae with and without infectious keratoconjunctivitis. J Wildl Dis. 2012;48:619-31.

14. Grymer J. Infektiøs bovin keratokonjunktivitis hos kvæg og rådyr. Dansk Vet Tidsskr. 1984;67:854-6.

15. Kummeneje K. Isolation of Neisseria ovis and a Colesiota conjunctivae-like organism from cases of kerato-conjunctivitis in reindeer in northern Norway. Acta Vet Scand. 1976;17:107-8.

16. Aschfalk A, Josefsen TD, Steingass H, Müller W, Goethe R. Crowding and winter emergency feeding as predisposing factors for kerato-conjunctivitis in semi-domesticated reindeer in Norway. Dtsch Tierarztl Wochenschr. 2003;110:295-8.

17. Sanchez Romano J, Marcin N, Josefsen TD, Nymo IH, Sørensen KK, Tryland M. Severe transmissible eye infection in reindeer: bacterium or virus? 64th Annual International Conference of the Wildlife Disease Association, Queensland; 2015. p. 26-30 (abstract 45, page 13).

18. Skjenneberg S, Slagsvold L. Reindriften og dens naturgrunnlag. Oslo: Universitetsforlaget; 1968

19. Tryland M, Stubsjøen SM, Ågren E, Johansen B, Kielland C. Herding conditions related to infectious keratoconjunctivitis (IKC) in semi-domesticated reindeer (Rangifer t. tarandus) in Norway and Sweden - a questionnairebased survey among reindeer herders. Acta Vet Scand. 2016;58:22. doi:10.1186/s13028-016-0203-X.

20. Ryeng KA, Arnemo JM, Larsen S. Determination of optimal immobilizing doses of a medetomidine hydrochloride and ketamine hydrochloride combination in captive reindeer. Am J Vet Res. 2001;62:119-26.

21. Ros C, Belak S. Studies of genetic relationships between bovine, caprine, cervine, and rangiferine alphaherpesviruses and improved molecular methods for virus detection and identification. J Clin Microbiol. 1999:37:1247-53.

22. Ros C, Belak S. Characterization of the glycoprotein B gene from ruminant alphaherpesviruses. Virus Genes. 2002;24:99-105.

23. Ek-Kommonen C, Pelkonen S, Nettleton PF. Isolation of a herpesvirus serologically related to bovine herpesvirus 1 from a reindeer (Rangifer tarandus). Acta Vet Scand. 1986;27:299-301.

24. Miller JM, van der Maaten MJ. Reproductive tract lesions in heifers after intrauterine inoculation with infectious bovine rhinotracheitis virus. Am J Vet Res. 1984:45:790-4.

25. Wang J, O'Keefe J, Orr D, Loth L, Banks M, Wakeley P, West D, Card R, Ibata G, Van Maanen K, Thoren P, Isaksson M, Kerkhofs P. Validation of a real-time PCR assay for the detection of bovine herpesvirus 1 in bovine semen. J Virol Meth. 2007;144:103-8.

26. Das Neves CG, Roger M, Yoccoz NG, Rimstad E, Tryland M. Evaluation of three commercial bovine ELISA kits for detection of antibodies against alphaherpesviruses in reindeer (Rangifer tarandus tarandus). Acta Vet Scand. 2009;51:9. doi:10.1186/1751-0147-51-9.

27. Das Neves CG, Thiry J, Skjerve E, Yoccoz N, Rimstad E, Thiry E, Tryland M. Alphaherpesvirus infections in semidomesticated reindeer: a crosssectional serological study. Vet Microbiol. 2009;139:262-9. doi:10.1016/j. vetmic.2009/06.013. 
28. Marin MS, Leunda MR, Verna AE, Morán PE, Odeón AC, Pérez SE. Distribution of bovine herpesvirus type 1 in the nervous system of experimentally infected calves. Vet J. 2016;209:82-6. doi:10.1016/j. tvjl.2015.10.034

29. Gould S, Dewell R, Tofflemire K, Whitley RD, Millman ST, Opriessnig T, Rosenbusch R, Trujillo J, O`Connor AM. Randomized blinded challenge study to assess association between Moraxella bovoculi and Infectious Bovine Keratoconjunctivitis in dairy calves. Vet Microbiol. 2013;164(12):108-15. doi:10.1016/j.vetmic.2013.01.038.

30. Jayappa HG, Lehr C. Pathogenicity and immunogenicity of piliated and nonpili-ated phases of Moraxella bovis in calves. Am J Vet Res. 1986;47:2217-21.

31. Rogers DG, Cheville NF, Pugh GW Jr. Pathogenesis of corneal lesions caused by Moraxella bovis in gnotobiotic calves. Vet Pathol. 1987;24:287-95.

32. Loy JD, Brodersen BW. Moraxella spp. isolated from field outbreaks of infectious keratoconjunctivitis: a retrospective study of case submissions from to 2013. J Vet Diagn Invest. 2010;2014(26):761-8. doi:10.1177/1040638714551403.

33. Angelos JA, Ball LM, Hess JF. Identification and characterization of complete RTX operons in Moraxella bovoculi and Moraxella ovis. Vet Microbiol. 2007;125:73-9.
34. Calcutt MJ, Foecking MF, Martin NT, Mhlanga-Mutangadura T, Reilly TJ. Draft genome sequence of Moraxella bovoculi strain 237T (ATCC BAA1259T) isolated from a calf with infectious bovine keratoconjunctivitis. Genome Announc. 2014;2:e00612-4. doi:10.1128/genomeA.00612-14.

35. Dickey AM, Loy JD, Bono JL, Smith TPL, Apley MD, Lubbers BV, DeDonder KD, Capik SF, Larson RL, White BJ, Blom J, Chitko-McKown CG, Clawson ML. Large genomic differences between Moraxella bovoculi isolates acquired from the eyes of cattle with infectious bovine keratoconjunctivitis versus the deep nasopharynx of asymptomatic cattle. Vet Res. 2016;47:31. doi:10.1186/s13567-016-0316-2.

36. Das Neves CG, MørkT, Godfroid J, Sørensen KK, Breines E, Hareide E, Thiry J, Rimstad E, Thiry E, Tryland M. Experimental infection of reindeer with cervid herpesvirus 2. Clin Vaccine Immunol. 2009;16:1758-65. doi:10.1128/CVI.00218-09.

37. Das Neves CG, Mørk T, Thiry J, Godfroid J, Rimstad E, Thiry E, Tryland M. Cervid herpesvirus 2 experimentally reactivated in reindeer can produce generalized viremia and abortion. Virus Res. 2009;145:321-8. doi:10.1016/j.virusres.2009.08.002.

38. O'Connor AM, Shen HG, Wang C, Opriesnig T. Descriptive epidemiology of Moraxella bovis, Moraxella bovoculi and Moraxella ovis in beef calves with naturally occuring infectious bovine keratoconjunctivitis (pinkeye). Vet Microbiol. 2012;155:374-80.

\section{Submit your next manuscript to BioMed Central and we will help you at every step:}

- We accept pre-submission inquiries

- Our selector tool helps you to find the most relevant journal

- We provide round the clock customer support

- Convenient online submission

- Thorough peer review

- Inclusion in PubMed and all major indexing services

- Maximum visibility for your research

Submit your manuscript at www.biomedcentral.com/submit 